\title{
The effect of ketamine on the separation anxiety and emergence agitation in children undergoing brief ophthalmic surgery under desflurane general anesthesia
}

\author{
Won Ju Jeong, Woon Young Kim, Man Gook Moon, Doo Jae Min, Yoon Sook Lee, Jae Hwan Kim, \\ and Young Cheol Park
}

Department of Anesthesiology and Pain Medicine, Ansan Hospital, Korea University College of Medicine, Ansan, Korea

Background: Emergence agitation (EA) frequently occurs after desflurane anesthesia in children. Ketamine, because of its sedative and analgesic properties, might be useful for the management of separation anxiety and EA. We investigated the preventive effect of ketamine on separation anxiety and EA after desflurane anesthesia in children for brief ophthalmic surgery.

Methods: Sixty children, ranging in age from 2-8 years old, undergoing brief ophthalmic surgery were randomly allocated to one of the 3 groups: group C received normal saline, group K1.0 received ketamine $1.0 \mathrm{mg} / \mathrm{kg}$ intravenously before entering the operating room, or group K0.5 received ketamine $0.5 \mathrm{mg} / \mathrm{kg} 10 \mathrm{~min}$ before the end of the surgery. Before induction, the separation anxiety score was evaluated. Extubation time, post-anesthesia care unit stay time, postoperative nausea and vomiting, emergence agitation, and pain were assessed.

Results: The group K1.0 had a lower separation anxiety score compared with groups K0.5 and C. Extubation time in group K0.5 was significantly prolonged compared with groups K1.0 and C. The incidence of EA and the modified Children's Hospital of Eastern Ontario Pain Scale were significantly lower in group K1.0 and group K0.5 compared to group C, but there was no significant difference between groups K1.0 and K0.5.

Conclusions: In children undergoing brief ophthalmic surgery with desflurane anesthesia, ketamine $1.0 \mathrm{mg} / \mathrm{kg}$ administered before entering the operating room reduced separation anxiety, postoperative pain, and incidence of EA without delay in recovery. (Korean J Anesthesiol 2012; 63: 203-208)

Key Words: Agitation, Children, Desflurane, Ketamine, Separation anxiety.

\footnotetext{
Received: July 29, 2011. Revised: 1st, November 7, 2011; 2nd, February 8, 2012; 3rd, March 14, 2012; 4th, April 3, 2012. Accepted: April 17, 2012. Corresponding author: Woon Young Kim, M.D., Ph.D., Department of Anesthesiology and Pain Medicine, Ansan Hospital, Korea University College of Medicine, 516, Gojan 1-dong, Danwon-gu, Ansan 425-707, Korea. Tel: 82-31-412-5291, Fax: 82-31-412-5294, E-mail: ckssis@korea.ac.kr (c) This is an open-access article distributed under the terms of the Creative Commons Attribution Non-Commercial License (http:// creativecommons.org/licenses/by-nc/3.0/), which permits unrestricted non-commercial use, distribution, and reproduction in any medium, provided the original work is properly cited.
} 


\section{Introduction}

Desflurane is a popular anesthetic in pediatric and ambulatory anesthesia. However, when desflurane is used alone, it causes children to have a higher incidence of EA. Rapid removal of residual anesthetics due to desflurane's low blood solubility has been suggested to cause incidences of emergence agitation (EA) [1]. EA is common in children [1-4]. EA causes discomfort and affliction to young patients and their guardians and can also lead to problems during recovery. There have been a number of studies over the causes of EA and preventive strategies against EA, but the pathogenesis and preventive methods are still controversial [4]. Preoperative anxiety is associated with a high incidence of problematic behavior on emergence from anesthesia [5,6]. Cole et al. [7] have shown that difficult separation of children from their parents is associated with a higher risk of developing postoperative delirium. Ketamine is an effective drug for sedation, analgesia, and amnesia. Additionally, ketamine may be useful for sedating excited and anxious children during the pre-surgical waiting period.

The purpose of this study was to compare the effect of injection ketamine between when ketamine was injected at 10 min before the completion of operation and when ketamine was injected as premedication before entering the operating room. The effect of ketamine injection was measured by the incidence of separation anxiety, EA, and side effects in children undergoing brief ophthalmic surgery under desflurane general anesthesia.

\section{Materials and Methods}

After the approval from the Institutional Review Board and informed consent of patients and guardians following full explanation of the purpose and the procedure of this study were obtained, the study was carried out. Sixty children, between the ages of 2-8 years, with American Society of Anesthesiologists physical status I-II, who were scheduled to undergo strabismus or entropion surgery under general anesthesia, were enrolled into this study. Children with cognitive or developmental disorders were excluded.

The 60 patients were randomly allocated to one of the 3 groups: the control group (administered saline solution, $\mathrm{n}=$ 20), the K0.5 group (administered $0.5 \mathrm{mg} / \mathrm{kg}$ of ketamine 10 min before the completion of operation, $\mathrm{n}=20$ ), and the K1.0 group (administered $1.0 \mathrm{mg} / \mathrm{kg}$ of ketamine before entering the operating room, $\mathrm{n}=20$ ).

Atropine $0.01 \mathrm{mg} / \mathrm{kg}$ was injected intramuscularly 30 min before the induction of anesthesia. Before entering the operating room, the control and group K0.5 received normal saline and the group K1.0 received ketamine $1.0 \mathrm{mg} / \mathrm{kg}$ intravenously. All medication was administered by personnel who were not involved in this study and total injected volume of medication was $5 \mathrm{ml}$ in total.

On arrival at the operating room, separation anxiety score was assessed on a simple 4-point scale as follows: 1 , calm child: no kind of intervention; 2, consolable child: requires only physical contact with parents; 3 , agitated child: a screaming and crying child; and 4, aggressive child: must be physically restrained to avoid harm [7]. We monitored the blood pressure, electrocardiogram, and pulse oximetry. Thiopental sodium $5 \mathrm{mg} / \mathrm{kg}$ and rocuronium $0.6 \mathrm{mg} / \mathrm{kg}$ were administered intravenously and an endotracheal intubation was performed. Anesthesia was maintained with oxygen $1.5 \mathrm{~L} / \mathrm{min}$, nitrous oxide $1.5 \mathrm{~L} / \mathrm{min}$ and desflurane at $4-6$ vol\%, while controlled ventilation was performed to sustain end-tidal carbon dioxide between 30 and $35 \mathrm{mmHg}$. Ten minutes prior to the end of surgery, ketamin or normal saline was administered by physician who was not participating in this study. The control and group K1.0 received normal saline and the group K0.5 recieved ketamine $0.5 \mathrm{mg} / \mathrm{kg}$ intravenously. The removal time of the speculum from eyelid defined the termination of surgery. At the end of surgery, administration of desflurane and nitrous oxide was discontinued, and then manual ventilation was performed with $100 \%$ oxygen $6 \mathrm{~L} / \mathrm{min}$. To reverse residual muscle relaxation, pyridostigmine $0.2 \mathrm{mg} / \mathrm{kg}$ and glycopyrrolate $0.008 \mathrm{mg} / \mathrm{kg}$ were administered. When gag reflex was restored and the patient showed facial grimaces or purposefulappearing motor movements, extubation was performed and the time period from the end of surgery to the extubation was recorded. The time span from the attachment of the monitoring equipments to the extubation was recorded as the duration of anesthesia, while the time span between the insertion and removal of the eyelid speculum was recorded as the duration of operation. After extubation, patients were transferred to the post-anesthesia care unit (PACU), where their EA was observed by nurse, who was blinded to the group of the patients. EA was assessed on a simple 4-point scale, same as separation anxiety [8]. On admission to the PACU and every $5 \mathrm{~min}$, patients' emergence behavior was measured and the highest score

Table 1. Modified CHEOPS (Children's Hospital of Eastern Ontario Pain Scale)

\begin{tabular}{llll}
\hline Score & \multicolumn{1}{c}{0} & \multicolumn{1}{c}{1} & \multicolumn{1}{c}{2} \\
\hline Cry & No cry & Crying, moaning & Scream \\
Facial & Smiling & Composed & Grimace \\
Verbal & Positive & None or other complaints & Pain complaint \\
Torso & Neutral & Shifting, tense, upright & Restrained \\
Legs & Neutral & Kicks, squirm, drawn up & Restrained \\
\hline
\end{tabular}


was recorded during the PACU stay. Postoperative pain was assessed by using the modified Children's Hospital of Eastern Ontario Pain Scale (CHEOPS) (Table 1) [9] on admission to the PACU, every 15 min until the discharge from the PACU. During the PACU stay, the highest score at any time was recorded. When the modified CHEOPS is more than 6, children were managed by giving fentanyl $1.0 \mu \mathrm{g} / \mathrm{kg}$ with at least a $10 \mathrm{~min}$ time interval between each dose and the administration was discontinued as soon as the symptoms were disappeared. Injection dose of fentanyl was $1 \mu \mathrm{g} / \mathrm{kg}$ as single bolus, but limited to $3 \mu \mathrm{g} / \mathrm{kg}$.

For evaluation of postoperative nausea and vomiting, a 4-point scale was employed to check the incidence of adverse events as follows: 1 , none; 2 , nausea only; 3 , one episode of vomiting; and 4, more than 2 episodes of vomiting. Recurrent vomiting within 5 minutes was regarded as one single episode. Ondansetron $0.15 \mathrm{mg} / \mathrm{kg}$ was provided for an antiemetic drug

Table 2. The Modified Aldrete Postanesthesia Score

\begin{tabular}{ll}
\hline \multicolumn{1}{c}{ Criteria } & Point value \\
\hline Oxygenation $^{\prime}$ & 2 \\
$\mathrm{SpO}_{2}>92 \%$ on room air & 1 \\
$\mathrm{SpO}_{2}>90 \%$ on oxygen & 0 \\
$\mathrm{SpO}_{2}<90 \%$ on oxygen & \\
Respiration & 2 \\
Breathes deeply and coughs freely & 1 \\
Dyspnoeic, shallow or limited breathing & 0 \\
Apnoea & \\
Circulation & 2 \\
Blood pressure \pm 20 mmHg of normal & 1 \\
Blood pressure $\pm 20-50$ mmHg of normal & 0 \\
Blood pressure more than \pm 50 mmHg of normal & \\
Consciousness & 2 \\
Fully awake & 1 \\
Arousable on calling & 0 \\
Not responsive & \\
Activity & 2 \\
Moves all extremities & 1 \\
Moves two extremities & \\
No movement &
\end{tabular}

and if the vomiting was not controlled, repeated administration was performed up to a total dose of $4 \mathrm{mg}$.

Modified Aldrete postanesthesia score (Table 2) [10] was adopted as the discharge criteria, according to which a score of more than 9 is required for discharge. Patients who fulfilled the discharge criteria were transferred to the ward unit and the PACU stay time was recorded.

Statistical analysis was performed using SPSS 12.0 (SPSS Inc., Chicago, IL, USA). Continuous variables such as age, height, weight, duration of anesthesia, duration of surgery, extubation time after the end of surgery, PACU stay time, and modified CHEOPS were confirmed to follow a normal distribution. Among the variables, extubation time and PACU stay time were reported as mean $\pm \mathrm{SD}$, which was analyzed using one-way ANOVA followed by Turkey test, while the other continuous variables were done using Kruskal-Wallis test. Categorical variables were compared using Chi-square test for sex and using Fisher's exact test for seperation anxiety score, postoperative nausea/vomiting scores, and EA scores. A P value less than 0.05 was considered statistically significant.

\section{Results}

Of the 60 patients, there were no statistically significant differences among the 3 groups in age, sex, height, weight, the duration of anesthesia, and operation (Table 3 ).

There were no significant differences in the PACU stay time and the incidence of postoperative nausea and vomiting among the 3 groups. However, extubation time in group K0.5 was significantly prolonged compared to the group K1.0 and the control (Table 4). The K0.5 and K1.0 groups showed a lower incidence of fentanyl injection compared to the control (Table 4). The group K1.0 revealed a lower separation anxiety score compared to groups K0.5 and control, respectively. The incidence of EA and the modified CHEOPS were significantly lower in groups K1.0 and K0.5 compared to control, but there was no significant difference between group K1.0 and group K0.5 (Table 5).

Table 3. Demographic Data

\begin{tabular}{lccc}
\hline \multicolumn{1}{c}{ Group } & $\mathrm{C}(\mathrm{n}=20)$ & $\mathrm{K} 1.0(\mathrm{n}=20)$ & $\mathrm{K} 0.5(\mathrm{n}=20)$ \\
\hline Age $(\mathrm{yr})$ & $4.80 \pm 0.41$ & $4.96 \pm 0.36$ & $4.99 \pm 0.39$ \\
Sex $(\mathrm{M}: \mathrm{F})$ & $11: 9$ & $10: 10$ & $10: 10$ \\
Height $(\mathrm{cm})$ & $110.59 \pm 2.99$ & $107.34 \pm 3.17$ & $105.90 \pm 3.25$ \\
Weight $(\mathrm{kg})$ & $20.46 \pm 1.30$ & $18.97 \pm 1.26$ & $18.78 \pm 1.27$ \\
Duration of anesthesia (min) & $56.85 \pm 2.39$ & $56.75 \pm 2.89$ & $56.30 \pm 2.23$ \\
Duration of operation (min) & $31.65 \pm 2.56$ & $29.45 \pm 2.80$ & $31.95 \pm 2.24$ \\
\hline
\end{tabular}

Values are mean \pm SD. There are no significant differences among the 3 groups. Group C: administration of normal saline. Group K1.0: administration of ketamine $1.0 \mathrm{mg} / \mathrm{kg}$ intravenously before entering the operating room. Group K0.5: administration of ketamine $0.5 \mathrm{mg} / \mathrm{kg} 10$ min before the end of the surgery. 
Table 4. Extubation Time, PACU Stay Time, Incidence of Fentanyl Injection, and Postoperative Nausea and Vomiting

\begin{tabular}{lccc}
\hline \multicolumn{1}{c}{ Group } & $\mathrm{C}(\mathrm{n}=20)$ & $\mathrm{K} 1.0(\mathrm{n}=20)$ & $\mathrm{K} 0.5(\mathrm{n}=20)$ \\
\hline Extubation time (min) & $7.34 \pm 0.32$ & $7.81 \pm 0.36$ & $9.99 \pm 0.39^{*}$ \\
PACU stay time (min) & $54.25 \pm 1.78$ & $55.00 \pm 2.32$ & $53.40 \pm 1.67$ \\
Incidence of fentanyl injection & $15 / 20$ & $6 / 20^{*}$ & $4 / 20^{*}$ \\
PONV $(1: 2: 3: 4)$ & $18: 2: 0: 0$ & $19: 0: 1: 0$ & $18: 1: 1: 0$ \\
\hline
\end{tabular}

Values of extubation time and delivery time are mean \pm SD. There are no significant differences among the 3 groups in delivery time and PONV. PONV (Postoperative nausea and vomiting) scale: 1 = none, 2 = retching, 3 = one episode of vomiting, $4=$ multiple episodes of vomiting. Group C: administration of normal saline. Group K1.0: administration of ketamine $1.0 \mathrm{mg} / \mathrm{kg}$ intravenously before entering the operating room. Group K0.5: administration of ketamine $0.5 \mathrm{mg} / \mathrm{kg} 10 \mathrm{~min}$ before the end of the surgery. ${ }^{*} \mathrm{P}<0.05$ compared with the Group C.

Table 5. Separation Anxiety Score, Pain Score (Modified CHEOPS) and Agitation Score

\begin{tabular}{llcc}
\hline \multicolumn{1}{c}{ Group } & C $(\mathrm{n}=20)$ & K1.0 $(\mathrm{n}=20)$ & K0.5 $(\mathrm{n}=20)$ \\
\hline Separation anxiety score $(1: 2: 3: 4)$ & $1: 6: 4: 9$ & $18: 2: 0: 0^{*, \dagger}$ & $0: 7: 5: 8$ \\
modified CHEOPS & $7.90 \pm 2.57$ & $4.00 \pm 2.49^{*}$ & $2.95 \pm 2.43^{*}$ \\
Agitation score $(1: 2: 3: 4)$ & $1: 2: 4: 13$ & $9: 4: 6: 1^{*}$ & $12: 5: 1: 2^{*}$ \\
\hline
\end{tabular}

Values of modified CHEOPS are mean \pm SD. Separation anxiety score: $1=$ asleep, $2=$ awake and calm, $3=$ agitated, but consolable, $4=$ severely agitated and inconsolable. Agitation score: $1=$ asleep, $2=$ awake and calm, $3=$ agitated but consolable, $4=$ severely agitated and inconsolable. Group C: administration of normal saline. Group K1.0: administration of ketamine $1.0 \mathrm{mg} / \mathrm{kg}$ intravenously before entering the operating room. Group K0.5: administration of ketamine $0.5 \mathrm{mg} / \mathrm{kg} 10 \mathrm{~min}$ before the end of the surgery. ${ }^{*} \mathrm{P}<0.05$ compared with the Group C. ${ }^{\dagger} \mathrm{P}<0.05$ compared with the Group K0.5.

\section{Discussion}

When desflurane is used alone, it causes children to have a higher incidence of EA. Rapid removal of residual anesthetics due to desflurane's low blood solubility has been suggested to cause incidences of EA [1]. Although the total intravenous anesthesia with propofol and remifentanil caused emergence as rapid as desflurane anesthesia, the incidence of EA after desflurane anesthesia was higher than propofol anesthesia [11]. Valley et al. [12] reported that deep extubation can be performed safely in anesthetized pediatric patients with desflurane or sevoflurane and EA was common in both groups.

Furthermore, the other etiology of EA include the lack of a young child's ability to adapt to sudden changes, especially in unfamiliar environments, immature neurologic development, separation anxiety, increased pain sensation, and sympathetic hyperactivity $[13,14]$.

EA is characterized by self-limiting aggressive agitation developed in the early phase of awakening from anesthesia at the end of surgery. EA carries the risk of children injuring themselves, their healthcare providers, their surgical repair, causing removal of drains, bleeding or pain at the surgical site, all of which can lead to the delay of discharge from the PACU [15]. Furthermore, it is not easy to differentiate between pain and EA in young patients, because they are able to express their pain and because EA disappears for the most part within $15 \mathrm{~min}$ [16].

According to Lim et al. [17], EA occurs far more frequently in pre-school aged children than in school aged children. The reason for this disparity is that pre-school aged children are far less able to acclimate themselves to the unfamiliar surroundings they may encounter upon emergence from anesthesia. Therefore, children participants in the current study were confined to between ages 2 and 8 years old, who were undergoing brief ophthalmic surgery. Eckenhoff et al. [18] reported that patients undergoing head and neck procedures may increase the incidence of emergence agitation. In addition, ophthalmology procedures in children may increase the incidence of emergence agitation. It is possible that when vision is disturbed following surgery and eye patching, the reactivity of the child to a hostile environment upon awakening from anesthesia may be distorted [19].

Ketamine is an $N$-methyl-D-aspartate (NMDA) receptor antagonist, which has strong analgesic effect at less than anesthesiainducting doses, does not cause respiratory depression at a small dose less than $1 \mathrm{mg} / \mathrm{kg}$, and affects heart rate and blood pressure insignificantly [20]. It is reported to possess strong preemptive analgesic effects and to suppress the occurrence of EA in children. The incidence of arousal responses such as nightmare or hallucination, which restrain clinical employment of ketamine, reaches $5-30 \%$ at a large dose of ketamine [21], but becomes lower at a smaller dose less than $1 \mathrm{mg} / \mathrm{kg}$ compared to opioids [22].

Karamaz et al. [23] showed that oral premedication with relatively high-dose ketamine reduced the incidence of EA in children undergoing adenotonsillectomy after desflurane 
anesthesia without delaying recovery. Kawaraguchi et al. [24] reported that an administration of ketamine $1 \mathrm{mg} / \mathrm{kg}$ after the induction of anesthesia and an instillation of ketamine 1 $\mathrm{mg} / \mathrm{kg} / \mathrm{hr}$ during operation in a pediatric strabismus surgery succeeded in decreasing EA. Kwak et al. [25] showed that intravenous injection of ketamine $1.0 \mathrm{mg} / \mathrm{kg}$, after the induction of anesthesia for young children undergoing tonsillectomy under general anesthesia with sevoflurane decreased the incidence of EA without delay in recovery.

In this study, we considered that the difficult separation of children from their parents when they enter into the operating room is associated with a higher risk of EA. And we compared the preventive effect of $1.0 \mathrm{mg} / \mathrm{kg}$ of ketamine as a premedicant to $0.5 \mathrm{mg} / \mathrm{kg}$ of ketamine, which administered $10 \mathrm{~min}$ before the completion of operation. In a preliminary study, $0.5 \mathrm{mg} /$ $\mathrm{kg}$ of ketamine as a premedicant was not sufficient to induce sedation. Thus, we decided to use $1.0 \mathrm{mg} / \mathrm{kg}$ of ketamine for premedication.

Lee et al. [26] reported that a dose of $0.25 \mathrm{mg} / \mathrm{kg}$ or $0.5 \mathrm{mg} / \mathrm{kg}$ of ketamine, intravenously administered $10 \mathrm{~min}$ prior to the end of surgery, successfully reduced the incidence of EA without any particular side-effects or delay in recovery. Several previous studies found that the injection of low dose ketamine before the end of surgery reduced the incidence of EA without a delay in recovery $[16,26]$. Therefore, we expected that extubation time would not be delayed in either K1.0 and K0.5. But, in this study, extubation time in group K0.5 was significantly prolonged compared to group K1.0 and control.

No premedication was given in the group C or group K0.5. This may be considered to be a limitation of our study, as preoperative anxiety may affect EA even if EA was no significant difference between groups K0.5 and K1.0

In conclusion, ketamine $1.0 \mathrm{mg} / \mathrm{kg}$ given intravenously for premedication reduces the incidence of EA and postoperative pain, as well as separation anxiety without delaying emergence.

\section{References}

1. Welborn LG, Hannallah RS, Norden JM, Ruttimann UE, Callan $\mathrm{CM}$. Comparison of emergence and recovery characteristics of sevoflurane, desflurane, and halothane in pediatric ambulatory patients. Anesth Analg 1996; 83: 917-20.

2. Jones RM, Cashman JN, Eger EI 2nd, Damask MC, Johnson BH. Kinetics and Potency of desflurane (I-653) in volunteers. Anesth Analg 1990; 70: 3-7.

3. Mellon RD, Simone AF, Rappaport BA. Use of anesthetic agents in neonates and young children. Anesth Analg 2007; 104: 509-20.

4. Davis PJ, Cohen IT, McGowan FX Jr, Latta K. Recovery Characteristics of desflurane versus halothane for maintenance of anesthesia in pediatric ambulatory patients. Anesthesiology 1994; 80: 298-302.

5. Aono J, Mamiya K, Manabe M. Preoperative anxiety is associated with a high incidence of problematic behavior on emergence after halothane anesthesia in boys. Acta Anaesthesiol Scand 1999; 43: 542-4.

6. Weldon BC, Bell M, Craddock T. The effect of caudal analgesia on emergence agitation in children after sevoflurane versus halothane anesthesia. Anesth Analg 2004; 98: 321-6.

7. Cole J, Murray D, McAllister J, Hirshberg G. Emergence behavior in chidren: defining the incidence of excitement and agitation following anaesthesia. Pediatr Anaesth 2002; 12: 442-7.

8. Aono J, Ueda W, Mamiya K, Takimoto E, Manabe M. Greater incidence of delirium during recovery from sevoflurane anesthesia in preschool boys. Anesthesiology 1997; 87: 1298-300.

9. McGrath PJ, Johnson G, Goodman JT, Schillinger J, Dunn J, Chapman JA. CHEOPS: a behavioral scale for rating postoperative pain in children. In: Advances in pain research and therapy. 9th ed. Edited by Field HL: New York, Raven Press. 1985, pp 395-402.

10. Aldrete JA. The post-anesthesia recovery score revisited. J Clin Anesth 1995; 7: 89-91.

11. Grundmann U, Uth M, Eichner A, Wilheim W, Larsen R. Total intravenous anaesthesia with propofol and remifentanil in paediatric patients: a comparison with a desflurane-nitrous oxide inhalation anaesthesia. Acta Anaesthesiol Scand 1998; 42: 845-50.

12. Valley RD, Freid EB, Bailey AG, Kopp VJ, Georges LS, Fletcher J, et al. Tracheal extubation of deeply anesthetized pediatric patients: a comparison of desflurane and sevoflurane. Anesth Analg 2003; 96: $1320-4$.

13. Uezono S, Goto T, Terui K, Ichinose F, Ishguro Y, Nakata Y. Emergence agitation after sevoflurane versus propofol in pediatric patients. Anesth Analg 2000; 91: 563-6.

14. Ebert TJ, Muzi M. Sympathetic hyperactivity during desflurane anesthesia in healthy volunteers. A comparison with isoflurane. Anesthesiology 1993; 79: 444-53.

15. Voepel-Lewis T, Malviya S, Tait AR. A prospective cohort study of emergence agitation in the pediatric postanesthesia care unit. Anesth Analg 2003; 96: 1625-30.

16. Abu-Shahwan I, Chowdary K. Ketamine is effective in decreasing the incidence of emergence agitation in children undergoing dental repair under sevoflurane general anesthesia. Paediatr Anaesth 2007; 17: 846-50.

17. Lim KJ, Choi KS, So KY, An TH. Comparison of incidences of emergence delirium from sevoflurane anesthesia in school and preschool children. Korean J Anesthesiol 2003; 44: 176-80.

18. Eckenhoff JE, Kneale DH, Dripps RD. The incidence and etiology of postanesthetic excitment. A clinical survey. Anesthesiology 1961; 22: 667-73.

19. Aouad MT, Nasr VG. Emergence agitation in children: an update. Curr Opin Anaesthesiol 2005; 18: 614-9.

20. Warncke T, Stubhaug A, Jorum E. Ketamine, an NMDA receptor antagonist, suppresses spatial and temporal properties of burninduced secondary hyperalgesia in man: a double blind, cross-over comparison with morphine and placebo. Pain 1997; 72: 99-106.

21. White PF, Way WL, Trevor AJ. Ketamine-its pharmacology and therapeutic uses. Anesthesiology 1982; 56: 119-36.

22. Dich-Nielsen JO, Svendsen LB, Berthelsen P. Intramuscular lowdose ketamine versus pethidine for postoperative pain treatment after thoracic surgery. Acta Anaesthesiol Scand 1992; 36: 583-7. 
23. Karamaz A, Kaya S, Turhanoglu S, Ozyilmaz MA. Oral ketamine premedication can prevent emergence agitation in chidren after desflurane anesthesia. Paediatr Anesth 2004; 14: 477-82.

24. Kawaraguchi Y, Miyamato Y, Fukumitsu K, Taniguchi A, Hirao O, Kitamura S, et al. The effect of ketamine on reducing postoperative agitation after sevoflurane anesthesia in pediatric strabismus surgery. Masui 2002; 51: 1343-8.

25. Kwak HJ, Kim JY, Kim JH, Kim YS, Park SY. The effect of ketamine and fentanyl on the incidence of emergence agitation after sevoflurane anesthesia in children undergoing tonsillectomy. Korean J Anesthesiol 2005; 49: 502-6.

26. Lee YS, Kim WY, Choi JH, Son JH, Kim JH, Park YC. The effect of ketamine on the incidence of emergence agitation in children undergoing tonsillectomy and adenoidectomy under sevoflurane general anesthesia. Korean J Anesthesiol 2010; 58: 440-5. 